\title{
Hydrothermal reactions of soda lime silica glass - revealing subsurface damage and alteration of mechanical properties and chemical structure of glass surfaces
}

\author{
Jiawei Luo, ${ }^{1,2}$ Hoang Huynh, ${ }^{1}$ Carlo G. Pantano, ${ }^{2,3}$ and Seong H. Kim ${ }^{1,2,3 *}$
}

1. Department of Chemical Engineering, Pennsylvania State University, University Park, PA, 16802, USA.

2. Materials Research Institute, Pennsylvania State University, University Park, PA, 16802, USA.

3. Department of Materials Science and Engineering, Pennsylvania State University, University Park, PA, 16802, USA.

* Corresponding author: Seong H. Kim (shkim@engr.psu.edu)

\begin{abstract}
Hydrothermal treatment provides a unique way to reveal subsurface damage of soda lime silica (SLS) float glass. During the hydrothermal treatment, the penetration of water, ionexchange, and hydrolysis reaction can take place. These reactions are accelerated at locations where subsurface damage exists. Interestingly, the hydrothermally-treated glass surface exhibits higher fracture toughness, lower hardness, and less resistance to mechanochemical wear at high humidity compared to the pristine SLS float glass. These property changes can be explained by the leaching and polymerization of the silicate network and the chemical environment of hydrous species in the surface region of SLS glass.
\end{abstract}

Keywords: hydrothermal reaction; subsurface damage; soda lime silica glass; water penetration; hydrous species; mechanical properties 


\section{Introduction}

The surface and subsurface damage of soda lime silica (SLS) glass can affect the strength and durability of the glass.[1-4] Such damage can be created when contact stresses are applied to the glass surface during the manufacturing, handling, and storage, but the severity of damage can be mediated through environmental effects. For example, adsorption of a monolayer of lubrication molecules on the surface can prevent physical wear at the sliding interface whereas interfacial shear in the presence of reactive molecules will damage and degrade the surface.[5,6] The history of normal indentation or interfacial shear at the surface can lead to a distribution of local chemical structures and residual stresses.[7-10] In the case of sharp cracks, tensile residual stress is believed to be present and, in humid environments, the crack will propagate in the direction where this residual stress is largest.[11] Changes in the stress profile in the surface region at the vicinity of the crack tip can be accompanied by changes in the chemical structure.[12] While it is generally accepted that these phenomena can be explained by stress corrosion mechanism,[13-15] revealing the subsurface damage and understanding their effect on mechanical properties and mechanochemical behavior is still challenging.

This study describes a method to reveal subsurface damage without using strong acid or base etching. Wong et al. showed that HF can be used to reveal subsurface damage on fused silica by controlling the etching rate precisely.[16] In this case, HF etching treatment reveals the subsurface damage at the cost of destroying the entire glass surface.[17] Since the subsurface damage is accompanied by residual stress which strains the silicate network, it is hypothesized that the associated strained bonds will preferentially react with water molecules. Here, it is shown that if reactions between the SLS glass surface and water are accelerated through 
hydrothermal treatment, the residual stress and related chemical structures can be etched selectively to map the damage on the surface.

Another outcome of this study was the observed alteration of mechanical properties and the mechanochemical response due to the hydrothermal leaching and hydration of the surface. For example, if the sodium ion leaching creates a softer layer or region on top of the bulk glass, indentation loading and unloading along the surface normal direction will be altered since the surface layer will be compacted and absorb more mechanical energy.[18] Recently, SLS glass has been found to show very unique wear resistance in high relative humidity environment.[5] While the mechanism of such mechanochemical wear behavior is not fully understood yet, the wear resistance was found to be related to the presence of sodium ions associated with the silicate network of SLS glass. The glasses without leachable sodium ions such as fused quartz, alkali-free display glass, and borofloat do not show the same wear resistant behavior at high humidity.[19,20] In aluminosicliate glasses where sodium is associated with aluminum tetrahedral sites instead of non-bridging oxygen in silicate network, the wear resistance at high humidity is not observed.[4] While removing the sodium ions from the surface region of SLS glass through thermal poling also removes the wear resistance effect of SLS glass, the silicate network is also altered drastically.[18] Therefore, a means to leach sodium out of SLS glass with no or minimal change in the subsurface network is needed to investigate the effect of sodium ions in mechanochemical wear resistance of the SLS glass.

In order to achieve these goals, hydrothermal reactions of SLS glasses were studied. Hydrothermal reactions are typically carried out in a sealed reactor at temperatures higher than $100{ }^{\circ} \mathrm{C}$.[21] During the hydrothermal treatment at $200{ }^{\circ} \mathrm{C}$ and $250{ }^{\circ} \mathrm{C}$, water can diffuse into alkali-free glasses and react forming Si-OH groups.[22,23] Such hydrothermal treatments in 
liquid water have been reported to strengthen a vitreous silica glass.[22,24] In the case of SLS glass, hydrothermal treatment in liquid water was reported to create a porous surface layer.[25] Our study investigated the effect of hydrothermal treatment in the vapor phase around $150{ }^{\circ} \mathrm{C}$ with the focus on the aforementioned goals - revealing the subsurface damage; studying mechanical properties of the modified surface layer; and investigating how the wear behavior is affected by sodium ion leaching. It should be noted that liquid water and water vapor have the same reactivity in hydrothermal reactions since their chemical potentials are the same at this saturated condition. However, transport properties in the vapor phase - especially the removal of reaction products from the glass - would be different than for the liquid phase.

\section{Experimental Details}

SLS float glass with a $1 \mathrm{~mm}$ thickness from Asahi Co. (Asahi Co., Tokyo, Japan) was used in this study. The bulk composition of SLS (weight \%) was found to be $72.3 \% \mathrm{SiO}_{2}, 13.3 \%$ $\mathrm{Na}_{2} \mathrm{O}, 7.7 \% \mathrm{CaO}, 1.9 \% \mathrm{Al}_{2} \mathrm{O}_{3}, 4.4 \% \mathrm{MgO}, 0.3 \% \mathrm{~K}_{2} \mathrm{O}$, and $0.1 \% \mathrm{Fe}_{2} \mathrm{O}_{3}$ from X-ray fluorescence (XRF). During the manufacturing process, $\mathrm{SO}_{2}$ treatment was applied after the glass was lifted from the tin bath onto the rollers, and this dealkalized the surface. This study investigated the air side of the float glass only because it is more pristine and defect free initially.[26]

The vapor-phase hydrothermal treatment system is schematically shown in Figure 1. It was performed in a sealed stainless steel vessel with a volume of $100 \mathrm{~cm}^{3} .10 \mathrm{~mL}$ of miliQ water was placed in the bottom of the vessel that was rinsed with ethanol and water before each treatment. The amount of water was enough to create saturated vapor between $100{ }^{\circ} \mathrm{C}$ and 200 ${ }^{\circ} \mathrm{C}$ in the sealed vessel. At $150^{\circ} \mathrm{C}$, the saturated water vapor pressure is $0.48 \mathrm{MPa}$. The actual 
temperature of the vessel was monitored with a thermocouple. All samples were cut in $2 \mathrm{~cm} \times 2$ $\mathrm{cm}$ and placed on an elevated sample stage in the vessel so that the glass would interact with saturated steam only. The sealed vessel was then put in an oven set to a desired temperature. After the hydrothermal treatment, the sealed vessel was rapidly cooled with running water. The treated samples were cleaned with miliQ water, pure ethanol and UV-ozone before any mechanical tests and surface characterizations.[27]

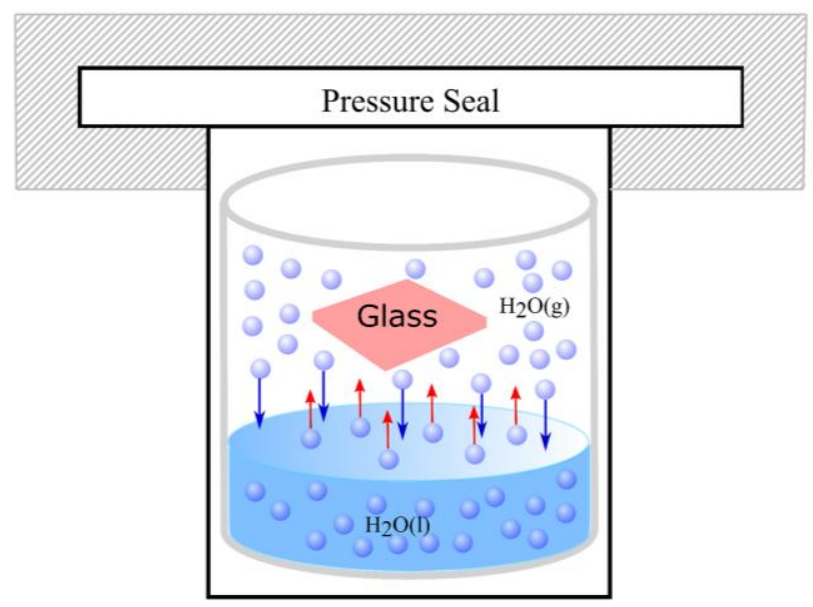

Figure 1. Schematic representation of vapor-phase hydrothermal treatment of SLS glass at temperatures higher than $100{ }^{\circ} \mathrm{C}$.

Specular reflectance infrared (SR-IR) spectroscopy was carried out with a Bruker Hyperion 3000 Microscope (Bruker, Co.) with a 15× objective lens. A gold mirror was used as a reference background. Attenuated total reflectance infrared (ATR-IR) spectroscopy was performed with the same IR microscope equipped with a Ge ATR crystal accessory with $60^{\circ}$ incident angle. Sum frequency generation (SFG) vibrational spectroscopy was used to study the chemical environment of hydrous species in the surface region of SLS glass. The detailed description of the SFG system can be found elsewhere.[28] In brief, visible laser pulses (532nm) 
from a $27 \mathrm{ps}$ Nd:YAG laser and tunable IR pulses $(2.5-10 \mu \mathrm{m})$ from an optical parameter generator and amplifier were spatially and temporally overlapped on a glass surface of interest. The incident angles of visible and IR pulses were $60^{\circ}$ and $56^{\circ}$ with respect to surface normal, respectively. The SFG signal was collected in a reflection geometry at the angle determined by the phase matching condition of the SFG process. The polarization combination used in this study was $s$ for SFG signal, $s$ for 532nm laser pulses, and $p$ for IR laser pulses (ssp).

The surface composition of SLS before and after hydrothermal treatment was analyzed with X-ray photoelectron spectroscopy (XPS). A Kratos Analytical Axis Ultra spectrometer (Chestnut, NY) fitted with a monochromatic AlKa $(1486.6 \mathrm{eV}) \mathrm{X}$-ray source was used. Survey scans of O 1s, Na KLL, Ca 2p, Mg KLL, C 1s, Si 2p peaks and high-resolution narrow binding energy of $\mathrm{O} 1 \mathrm{~s}$ and $\mathrm{C} 1 \mathrm{~s}$ peaks, were conducted at 80 and $20 \mathrm{eV}$ pass energies, respectively. The binding energies of all elements were corrected with the adventitious alkyl peak at $285 \mathrm{eV}$. The surface composition was determined after removing the adventitious carbon and carbonate species on the glass surface.[29]

Nanomechanical properties including elastic modulus and hardness of the hydrothermal treated surface were obtained using a nanoindenter (Hysitron TI 950, Minneapolis, MN) equipped with a Berkovich tip. The nanoindenation measurements was performed with displacement control. The maximum penetration depth was held at $50 \mathrm{~nm}, 100 \mathrm{~nm}, 150 \mathrm{~nm}$ and $200 \mathrm{~nm}$ for 2 seconds. The loading and unloading rate were both $20 \mathrm{~nm} / \mathrm{s}$. The results are averaged from more than 40 indentations for each indentation depth. Vickers indentation was performed with a microindenter (MHT Series 200; Leco Corporation, St. Joseph, MI). The duration time at maximum load was 15 seconds. The Vickers hardness was averaged from more than 15 measurements for each sample. The duration at maximum load for both nanoindentation 
and Vickers indentation are small enough that influence from indentation creep effect will not be significant.[30] Wear test was done using a custom-designed ball-on-flat tribometer with an environment control capability. All wear tests were conducted with $0.2 \mathrm{~N}$ normal force and 400 reciprocating sliding cycles. The ball used in this test was a borosilicate ball with $2.4 \mathrm{~mm}$ diameter (McMaster-Carr Products Inc., Elmhurst, IL). The contact pressure was calculated to be $350 \mathrm{MPa}$ based on Hertzian contact mechanics. "Invisible" wear tracks, tracks that did not undergo plastic deformation during the reciprocating shear loading, were created by performing the wear test in n-pentanol vapor environment.[5,31] The wear tracks before and after hydrothermal treatment were analyzed with an optical profilometer (Zygo NV7300, Middlefield, CT).

\section{Results and Discussion}

\subsection{Selective etching of regions with subsurface damage or residual stress via vapor-phase hydrothermal reaction}

Stress corrosion is a phenomenon that accelerates hydrolysis reactions of glass upon application of mechanical stress to the glass; $[14,32,33]$ a similar effect could be expected when a glass with residual stress is exposed to hydrolysis reaction conditions. The subsurface damage could be associated with subsurface defects such as non-bridging oxygen (NBO), threecoordinated silicon, and strained silica tetrahedron.[34] It was hypothesized the hydrothermal treatment can reveal the residual stress in the surface region since the defect sites or areas would react more readily with water at high temperature and pressure. To test this hypothesis, we ran two control tests: (i) hydrothermal reactions of the surface subjected to interfacial shear and (ii) 
hydrothermal reactions of an indentation crack. The diffusion and chemical reactions of water can lead to selective etching of these defective regions without using any chemical etchants such as strong alkali or hydrofluoric acid.
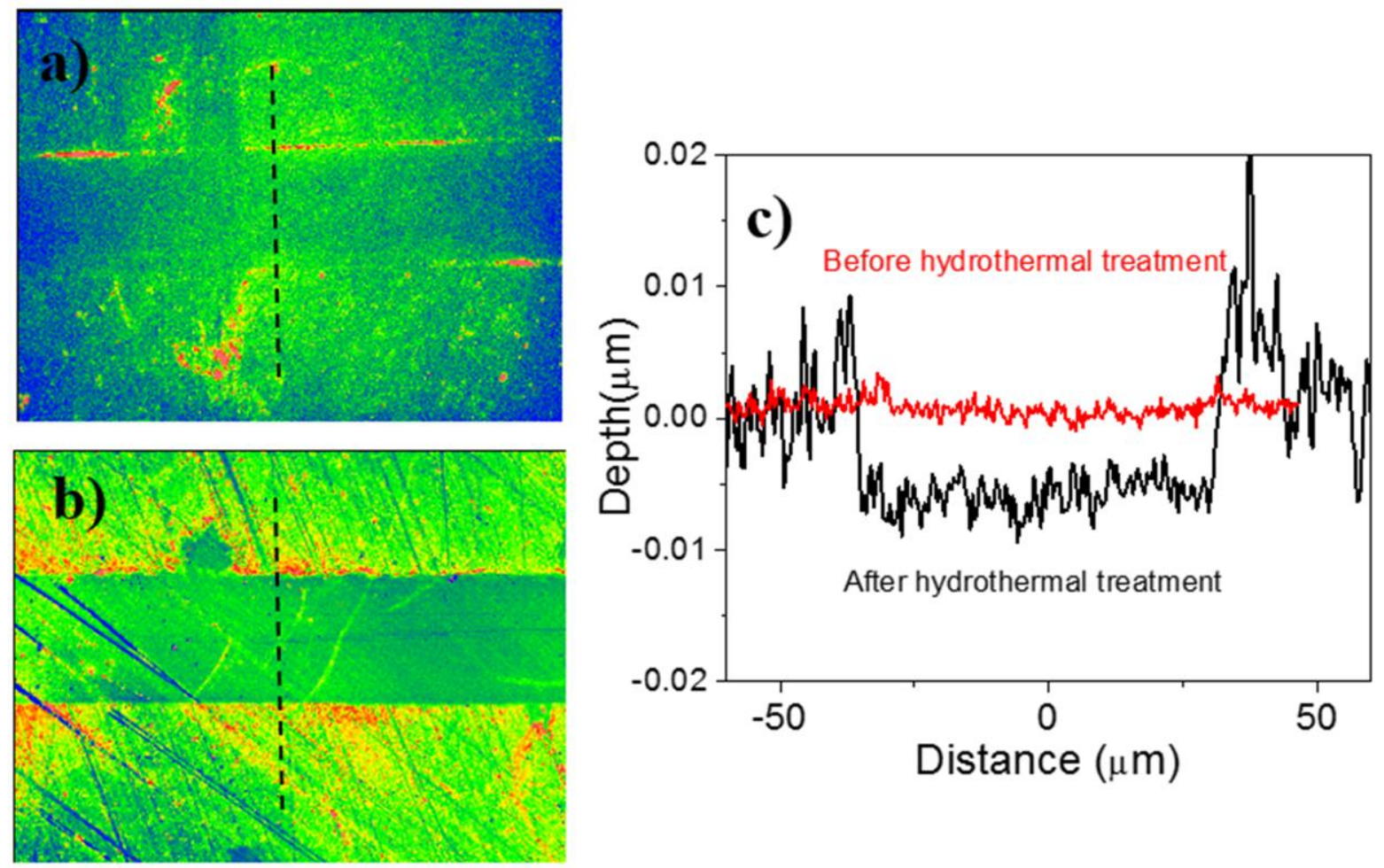

Figure 2. Optical profilometry of SLS glass surface slide tracks produced in n-pentanol VPL environments (a) before and (b) after hydrothermal treatment at $150{ }^{\circ} \mathrm{C}$ for 24 hours; (c) crosssection line profiles of the wear tracks marked with dashed lines in (a) and (b).

It is known that as long as the bulk can support the applied load, the 'visible' wear of the glass surface can be suppressed by continuous adsorption and replenishment of alcohol molecules from the vapor phase.[5,20,31] This is called vapor phase lubrication (VPL). The key for the success of VPL is to avoid detrimental reactions at the sliding interface that can induce chemical wear of the surface. Although the formation of visible wear tracks can be suppressed in 
VPL, the interfacial shear under a high normal load ( 350 MPa in the test condition used in this study) could leave some damage in the subsurface glass network. Figure 2 demonstrates how this “invisible" wear track with subsurface damages can be revealed by hydrothermal treatments. Figure $2 \mathrm{a}$ and $2 \mathrm{~b}$ compare the optical profilometry images of the same wear track before and after hydrothermal treatment. Figure $2 \mathrm{c}$ compares the cross section of wear tracks before and after hydrothermal treatment. The wear track became approximately $50 \mathrm{~nm}$ lower than the outside surface after hydrothermal treatment. This result clearly supports the hypothesis that the region with subsurface damage is more reactive than the pristine surface and can be preferentially etched by water under hydrothermal conditions.
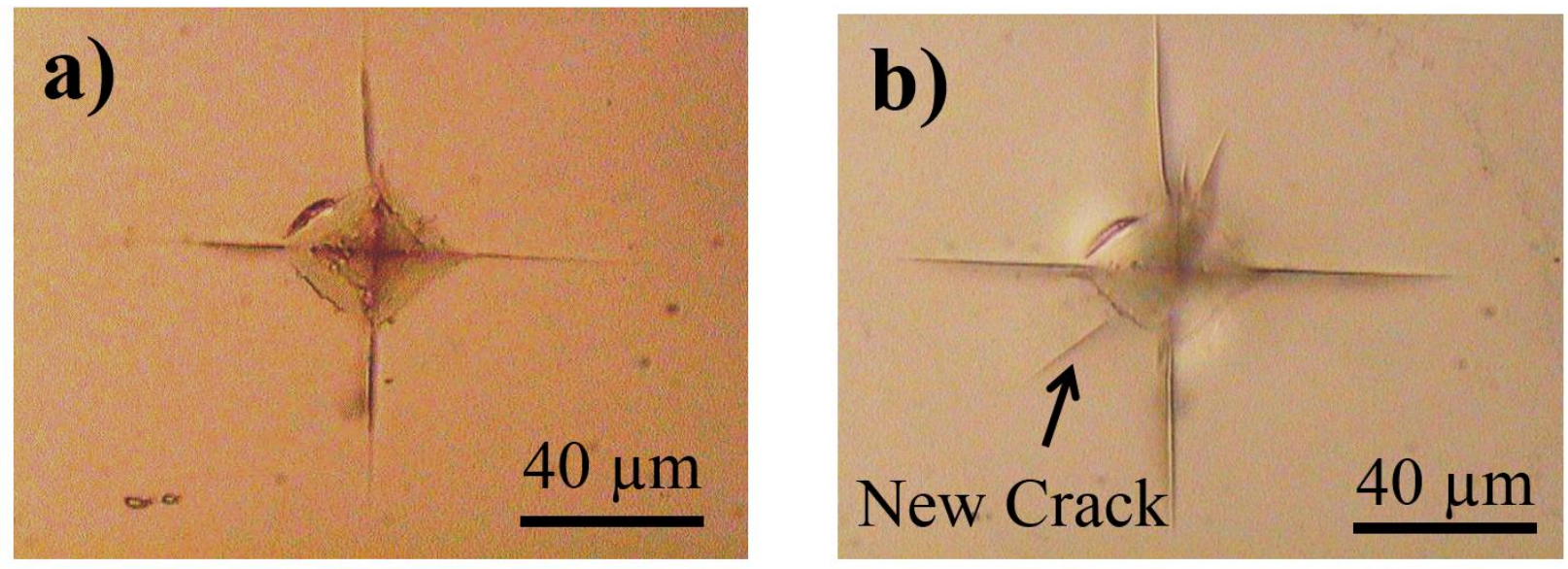

Figure 3. (a) Vickers indent prepared with $500 \mathrm{gf}$ load in $40 \%$ relative humidity; (b) indent from (a) after hydrothermal treatment at $150{ }^{\circ} \mathrm{C}$ for 24 hours.

Vickers indentation can be used to create regions with residual stress; when a radial crack is formed, the region in front of the crack tip is under residual stress.[3,35,36] As shown in Figure 3a, radial cracks were normally formed on the SLS float glass after indenting with a 500 
gf normal load in $40 \%$ relative humidity air. After the sample was hydrothermal treated at $150{ }^{\circ} \mathrm{C}$ for 24 hours, the length of the cracks was increased by $22 \%$. For some indents, new cracks were also formed as shown in Figure 3b. Again, this result supports that the glass surface with residual stress around crack tips can be selectively etched by hydrothermal treatment.

\subsection{Mechanical properties of hydrothermally-treated SLS glass surface}

The elastic modulus and hardness of the glass surface before and after hydrothermal treatment were measured with nanoindentation and are summarized in Figure 4. The elastic modulus and hardness were calculated from force-displacement curves using the Oliver-Pharr model.[37] The analysis was performed with four different indentation depths: 50nm, 100nm, $150 \mathrm{~nm}$, and $200 \mathrm{~nm}$. Since a surface layer with a modified chemical structure is expected to form during the hydrothermal treatment, the Poisson's ratio of the modified layer cannot be determined accurately. Therefore, the reduced modulus is reported rather than elastic modulus. It should be noted that the modified layer formed by hydrothermal treatment is not like an external film with an abrupt interface with the bulk substrate, but rather is a gradient layer that gradually changes in chemical and physical properties from the surface to the bulk. For these reasons, the accurate determination of mechanical properties for the modified layer was difficult; however, the qualitative trend of modulus and hardness for the modified layer can still be analyzed. 

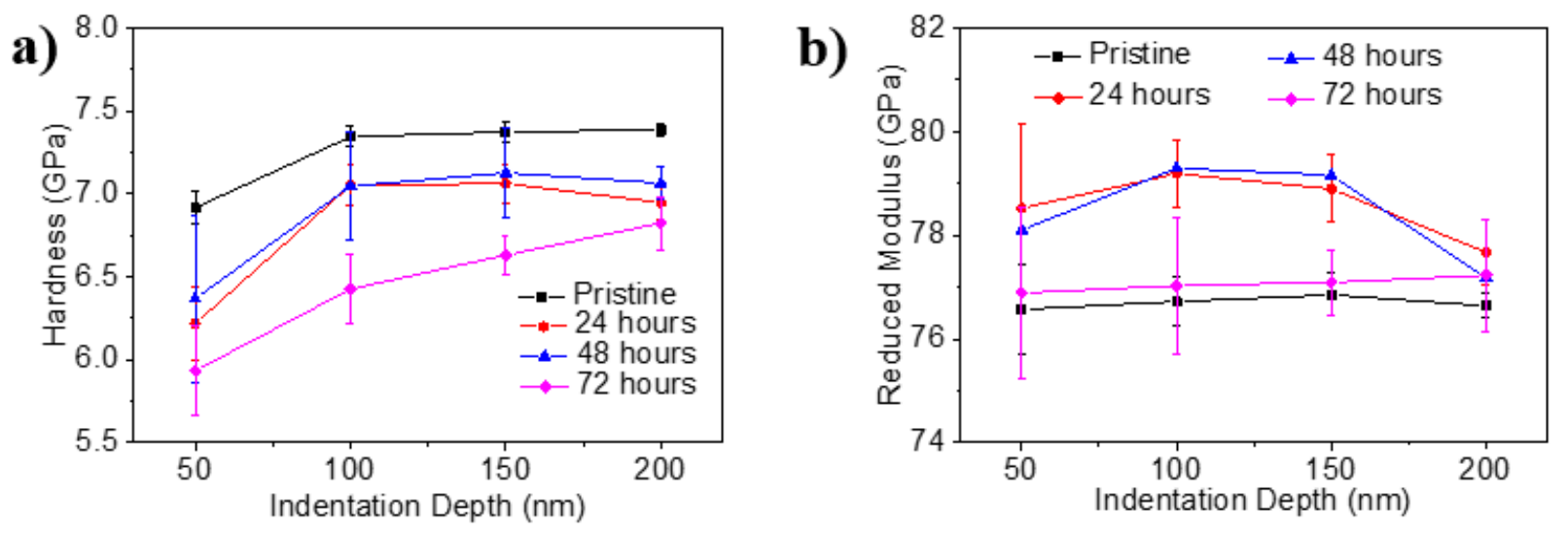

Figure 4. (a) Hardness and (b) reduced modulus of the SLS glass surfaces before and after hydrothermal treatment determined from nanoindentaiton.

Figure 4a shows that the overall hardness decreases after the hydrothermal treatment. This indicates that the silicate network is altered due to the reaction with water in the surface region, which could result in a hydrated layer. The longer treatment makes the glass surface softer, which can be associated with the thickening of a modified layer. As shown in Figure 4b, the reduced modulus of the surface treated for 24 and 48 hours is slightly higher than the pristine glass surface, and the surface hydrothermal treated for 72 hours is similar to the pristine surface. This non-monotonic trend must be related to an artifact associated with the modulus calculation in nanoindentation. When a soft layer is present on top of the glass, the softer layer could pile up around the probe tip during the indentation. Then the actual contact area is hard to determine from the indentation curves and could be larger than the area estimated from contact depth based on Oliver-Pharr method. As a result, the contact area estimated by the Oliver-Pharr method could be smaller than the actual contact area, leading to an overestimation of the reduced modulus.[38] In such a case, as the ratio of the indentation depth over film thickness increases, the reduced modulus will increase, reach a maximum, and then decrease. The reduced modulus estimated by 
the Oliver-Pharr method is smaller for the 72 hour sample than for the samples treated for 24 hours and 48 hours since a thicker modified layer is expected for SLS glass that has been hydrothermally treated for 72 hours and the ratio of the indentation depth over film thickness.[38]
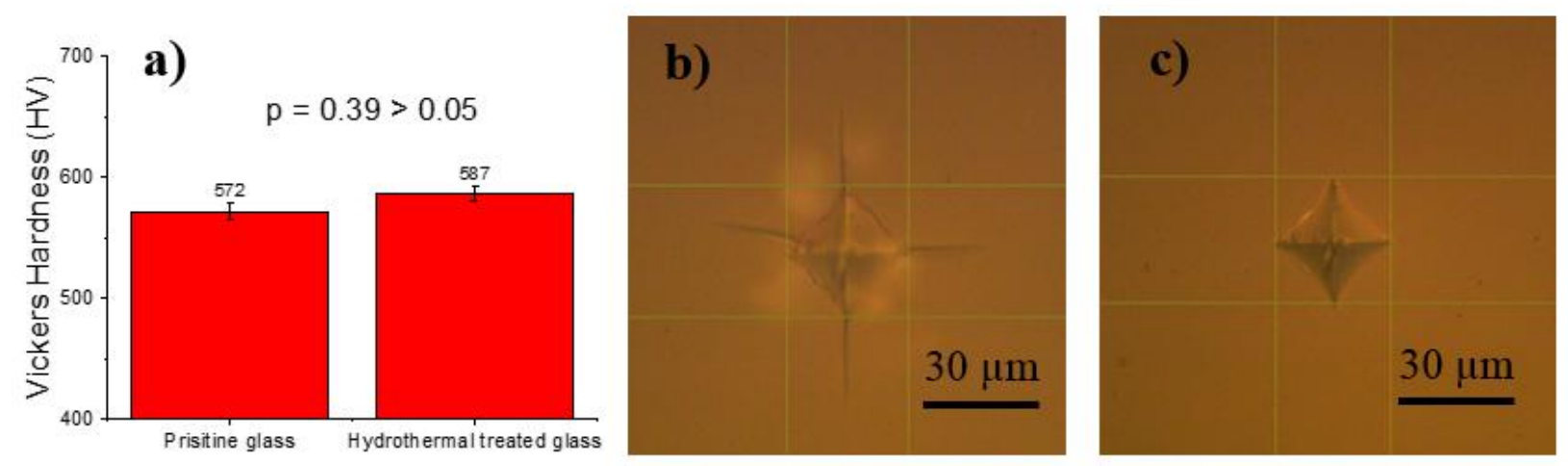

Figure 5. Vickers indentation before and after hydrothermal treatment at $150{ }^{\circ} \mathrm{C}$ for 72 hours under 300 gf load conditions at 40\% relative humidity. (a) Summary of Vickers hardness; (b) Optical image of Vickers indentation of SLS glass before hydrothermal treatment; (c) Optical image of Vickers indentation of SLS glass after hydrothermal treatment.

Resistance to the nucleation of a crack in glass is a desirable property. Vickers indentation was performed with 300 gf on the SLS glass surface before and after hydrothermal treatment. Figure 5a summarizes the Vickers hardness before and after hydrothermal treatment. It should be noted that the hardness obtained from Vickers indentation is smaller than that from nanoindentation. This is because the Berkvich tip used in nanoindentation has a smaller size and a different shape than the Vickers tip used in microindentation.[39] The student t-test suggests that the difference in Vickers hardness is not statistically significant with $95 \%$ confidence $(\mathrm{p}=$ $0.39>0.05$ ), which indicates that the bulk mechanical properties do no change by the hydrothermal treatment. No cracks are observed on the samples that are hydrothermal treated at 
$150{ }^{\circ} \mathrm{C}$ for 72 hours (Figure 5c) while the pristine SLS glass (Figure 5b) shows radial cracks from the Vickers indenter corners. Based on the nanomechanical properties of the hydrothermally treated surface determined in Figure 4, the surface layer formed by hydrothermal treatment is softer than the bulk. Thus, the resistance to crack formation after hydrothermal treatment cannot not be due to the compressive stress as is observed in chemically strengthened glass surface through ion-exchange process.[40] Instead, it must be due to the formation of a softer layer with modified chemical structure on top of the glass. The effect of such a modified layer formed from the bulk glass itself on fracture toughness of the surface has not been fully understood. One possible explanation is that the formation of the silica-like surface layer can prevent or suppress crack opening or initiation. This speculation is based on the fact that silica glass has higher fracture toughness than SLS glass.[18] Another possible explanation could be the changes in the network connectivity in the modified surface layer based on the topological constraint theory.[41] It is conceivable that the overall topological constraint in hydrothermallymodified surface region of SLS glass is altered since the number of Na-NBO sites decreases and hydrous species are introduced.[42]

\subsection{Mechanochemical wear of hydrothermally-treated SLS glass surface}

Unlike the alcohol VPL which prevents wear of the surface, water adsorption from the surrounding gas phase can induce mechanochemical wear due to hydrolysis reactions facilitated by interfacial shear.[43-45]The mechanochemical wear behavior of SLS glass shows a very unique humidity dependence.[19,20] Unlike other glass surfaces that show more wear as humidity in the test environment increases, SLS glass shows a decrease in wear as humidity increases, especially in near-saturation humidity.[44] While exact mechanisms of such 
resistance to mechanochemical wear at high humidity are not fully understood yet, it is believed to come from dynamic interactions between leachable $\mathrm{Na}^{+}$ions and the silicate network in the presence of water molecules.[18] XPS analysis indicates that sodium ions are almost completely depleted in the hydrothermal-treated SLS glass surface (see Supporting Information). Thus, if the hypothesis involving the leachable $\mathrm{Na}^{+}$ions is correct, it is expected that the resistance to mechanochemical wear at high humidity is reduced or lost for the hydrothermal-treated SLS glass surface.
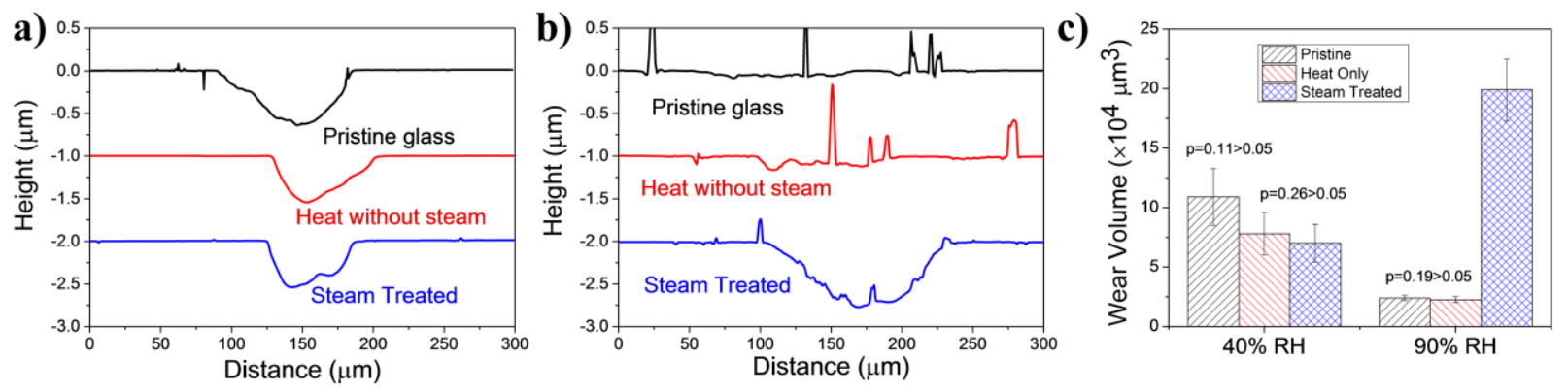

Figure 6. Comparison of wear tracks formed after 400 sliding cycles in (a) $40 \%$ relative humidity (b) $90 \%$ relative humidity on the pristine sample, the sample treated at $150{ }^{\circ} \mathrm{C}$ for 24 hours in dry air, and the sample treated at $150{ }^{\circ} \mathrm{C}$ for 24 hours in steam. (c) Comparison of the wear volume. The p-values in the figures are from comparison between two cases: pristine vs. heat-only and heat-only vs. steam-treated for the $40 \%$ humidity case and pristine vs. heat-only for the $90 \%$ humidity case.

The cross sections of the wear tracks produced at $40 \%$ and $90 \%$ relative humidity conditions for SLS glass surfaces before hydrothermal treatment and after heat treated at $150{ }^{\circ} \mathrm{C}$ for 24 hours in dry air and in steam are compared in Figure 6. The heat treatment in dry air was conducted to rule out the effect of thermal annealing on the wear behavior of SLS glass. As shown in Figures 6a, the wear behavior of SLS glass at $40 \%$ relative humidity is 
indistinguishable for the pristine, heat-treated, and hydrothermal-treated surfaces (the p-values from $t$-test are provided in Figure 6c). However, the wear depth and wear volume at $90 \%$ relative humidity are significantly increased after hydrothermal treatment, while both pristine and heatonly treated SLS glasses show very little wear (Figures 6b and 6c). In Figure 6b, small positive spikes on the substrate surfaces are physical wear debris of the counter surface deposited on the SLS surface.[19] The increase in wear volume at $90 \%$ relative humidity compared to the $40 \%$ relative humidity case is similar to the mechanochemical wear behaviors of other glasses without leachable sodium ions.[4,20] The results shown in Figure 6 clearly show that the resistance to mechanochemical wear at high humidity is a unique property for the SLS glass network containing leachable sodium ions; once sodium ions are depleted, the mechanochemical wear resistance effect is lost.

\subsection{Subsurface structural changes upon vapor-phase hydrothermal reactions}

It is generally known that during the hydrothermal treatment, molecular water can diffuse into the SLS glass and induce the hydrolysis of the silicate network at the bonding oxygen sites:

$$
\mathrm{Si}-\mathrm{O}-\mathrm{Si}+\mathrm{H}_{2} \mathrm{O} \Leftrightarrow \mathrm{Si}-\mathrm{OH}+\mathrm{HO}-\mathrm{Si}
$$

or the ion-exchange at the non-bonding oxygen (NBO) sites:[11,46,47]

$$
\begin{gathered}
\mathrm{Si}-\mathrm{O}^{-} \mathrm{Na}^{+}+H^{+} \Leftrightarrow \mathrm{Si}-\mathrm{OH}+\mathrm{Na}^{+} \\
\mathrm{Si}_{-} \mathrm{O}^{-} \mathrm{Na}^{+}+\mathrm{H}_{3} \mathrm{O}^{+} \Leftrightarrow \mathrm{Si}-\mathrm{OH}+\mathrm{Na}^{+}+\mathrm{H}_{2} \mathrm{O} .
\end{gathered}
$$

While these reactions are slow at ambient conditions, they can be significantly accelerated at a temperature higher than $100{ }^{\circ} \mathrm{C} .[13,48-50]$ First, the diffusion of water penetrating into the glass 
network is accelerated at elevated temperatures.[51] Second, the reactivity of water molecules is also higher. For example, the ionization constant of water $\left(\mathrm{K}_{\mathrm{w}}\right)$ at $150{ }^{\circ} \mathrm{C}$ is approximately 2 orders of magnitude higher than the value at room temperature.[52,53] In other words, the equilibrium concentration of protons and hydroxides are 10 times higher than normal water at room temperature. And, their thermal energy is higher compared to the ambient condition. Thus, hydroxide ions can catalyze the hydrolysis reaction (Eq.1) and the protons and hydronium ions can facilitate the sodium leaching reaction (Eq. 2 and 3). These reactions can occur not only when glass is in contact with liquid water, but also when the glass surface is exposed to steam at high temperature and pressure. It is conceivable that such reactions would occur more readily at the defect sites with strained chemical bonds, which can explain selective etching of the 'invisible' wear track formed in the n-pentanol VPL condition (Figure 2) and the region with residual tensile stress in front of a crack tip (Figure 3).
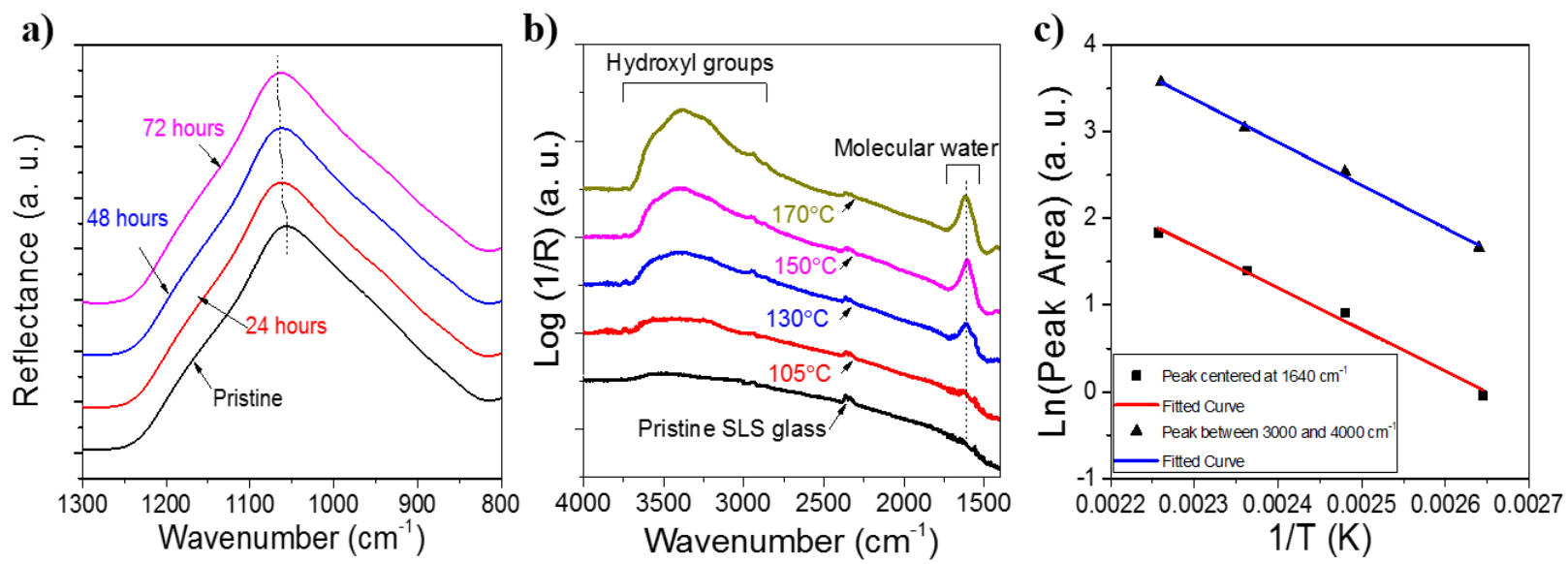

Figure 7. (a) SR-IR spectra of SLS glass before and after hydrothermal treatment. The treatment conditions is at $150{ }^{\circ} \mathrm{C}$ for 24 hours, 48 hours and 72 hours; (b) ATR-IR spectra of SLS glass before and after hydrothermal treatment for 12 hours at various temperatures; (c) Raw data and fitted curve for determining the activation energy of diffusion of water and formation of silanol groups into the glass network. 
In order to understand the mechanical and mechanochemical property changes of SLS glass after hydrothermal treatment, analyses of the silicate network structure as well as the amount of and chemical environment of hydrous species (silanol groups and molecular water) were carried out. Figure 7a shows the SR-IR analysis on the changes of silicate network before and after hydrothermal treatment. As the reaction time between glass surface and water increases, the peak centered around $1056 \mathrm{~cm}^{-1}$ gradually shifts to $1064 \mathrm{~cm}^{-1}$. In previous studies, this shift was normally observed at the surfaces where the density decreased due to the sodium depletion and the silicate network became a more silica-like structure.[54,55] These findings indicate that substantial reactions occur between water and glass surface during the hydrothermal treatment, modifying the subsurface silicate network structure.

The reactions between glass surface and water, and the diffusion of water molecules into the glass network, can be studied by examining hydrous species in the surface region before and after hydrothermal treatment. ATR-IR analysis was carried out to monitor the changes in the amount of these hydrous species in the subsurface of SLS glass. The information depth of ATRIR is about $0.5-0.7 \mu \mathrm{m}$ for the stretching vibration region of hydroxyl groups and $\sim 1.1 \mu \mathrm{m}$ for the bending vibration region of molecular water.[56,57] As shown in Figure 7b, the molecular water peak at $\sim 1620 \mathrm{~cm}^{-1}$ grows as the hydrothermal treatment temperature increases. This provides direct evidence that water molecules diffuse into the glass network. The activation energy $\left(E_{a}\right)$ for molecular water diffusion into the SLS glass can be obtained by assuming the Arrhenius relationship between the rate of diffusion $(k)$ and temperature (T):

$$
k=A \operatorname{Exp}\left[-E_{a} / R T\right] \quad \text { Eq. } 4
$$


where $A$ is a pre-exponential factor. Since $k$ is in a linear relationship with the amount of water molecules in the glass which is linearly proportional to the peak area $(M)$ of the water bending vibration, $k$ can be substituted with $b \times M$ where $b$ is a constant. Then, equation (4) can be expressed as follows:

$$
\operatorname{Ln}(M)=-\frac{E_{a}}{R} \frac{1}{T}-\operatorname{Ln}\left(\frac{b}{A}\right) \quad \text { Eq. } 5
$$

By fitting the experimental data (Figure 7c) with a linear relationship in equation (4), $E_{a}$ for diffusion of molecular water is calculated to be $40 \pm 2.8 \mathrm{~kJ} / \mathrm{mol}$.

In the $\mathrm{OH}$ stretch region of mid-IR spectra of glasses, both silanol ( $\mathrm{Si}-\mathrm{OH})$ and molecular water $\left(\mathrm{H}_{2} \mathrm{O}\right)$ are detected. The small peak at $\sim 3740 \mathrm{~cm}^{-1}$ is assigned to free $\mathrm{OH}$ of molecular water without hydrogen bonding with surrounding molecules.[58,59] Although not well-resolved, the steep rise and shoulder in the $\sim 3650 \mathrm{~cm}^{-1}$ region suggests the presence of a distinctive $\mathrm{OH}$ component; when it is deconvoluted through peak fitting, the $\sim 3650 \mathrm{~cm}^{-1}$ component is generally assigned to free $\mathrm{Si}-\mathrm{OH}$ without hydrogen-bonding with surrounding oxygen atoms.[60] All other components contributing to the broad feature from $3600 \mathrm{~cm}^{-1}$ and $2600 \mathrm{~cm}^{-1}$ can be assigned to $\mathrm{OH}$ groups (of both $\mathrm{Si}-\mathrm{OH}$ and $\mathrm{H}_{2} \mathrm{O}$ ) with varying degrees of hydrogen bonding interactions.[61,62] In previous literature, the broad $\mathrm{OH}$ stretch peaks were fitted with an arbitrary number of components and varying peak widths and the component near $3400 \mathrm{~cm}^{-1}$ was attributed to the molecular water in the glass network. $[60,63,64]$ But, it should be noted that the deconvolution of the hydrogen-bonded $\mathrm{OH}$ stretch peaks cannot be done through such a simple curve fitting procedure. The $\mathrm{OH}$ peak position and width are complicated functions of hydrogen bonding strengths and dynamics.[65] For that reason, we did not attempt to deconvolute the broad $\mathrm{OH}$ stretch peak (Figure 7b). 
It is noted that the Arrhenius plot of the $\mathrm{OH}$ stretching peak from $2600 \mathrm{~cm}^{-1}$ to $3800 \mathrm{~cm}^{-1}$ show $40.6 \pm 1.2 \mathrm{~kJ} / \mathrm{mol}$ (Figure $7 \mathrm{c}$ ), which is the same as the molecular water diffusion. This implies that the production of the Si-OH species is either limited or controlled by the diffusion of molecular water $\left(\mathrm{H}_{2} \mathrm{O}\right)$ or the transport rate of proton or hydronium ions $\left(\mathrm{H}^{+} / \mathrm{H}_{3} \mathrm{O}^{+}\right)$is similar to the diffusion of molecular water. The former would accelerate the hydrolysis reaction (Eq.1) and the latter would accelerate the reaction of ion-exchange with sodium ions (Eqs. 2 and 3).

The $E_{a}$ value determined for diffusion in SLS glass under vapor phase hydrothermal conditions is lower than the activation energy determined for pure silica glass. The $E_{a}$ for water diffusion in the pure silica glass was reported to be $\sim 70 \mathrm{~kJ} / \mathrm{mol}$ by Wiederhorn et al and Zouine et al in the same temperature range and saturated vapor pressure.[22,66] For reactions between water and silica glass at $400{ }^{\circ} \mathrm{C}-1000{ }^{\circ} \mathrm{C}$, the activation energy for water penetration into the glass and formation of $\mathrm{Si}-\mathrm{OH}$ was found to be $\sim 83 \mathrm{~kJ} / \mathrm{mol}$ or higher.[67] It should be noted that during the reaction between water and silica glass in their studies, $\mathrm{Si}-\mathrm{OH}$ is formed as a reaction product from the hydrolysis reaction.

The lower activation energy determined for SLS glass must be related to its alkali content and silicate network. Leaching of $\mathrm{Na}^{+}$in SLS glass has been proven to assist the water diffusion into its silica network.[57] The ion-exchange between $\mathrm{Na}^{+}$and hydronium ions results in the formation of $\mathrm{Si}-\mathrm{OH}$ from $\mathrm{NBO}$ sites and molecular water in the glass network. The silicate network of SLS glass is also quite different from the silica network of pure silica glass. Based on molecular dynamics (MD) simulations, Tilocca et al suggested that the addition of modifiers like $\mathrm{Na}^{+}$can change the ring size distribution in the Si-O-Si network, which can create more open pathways for water molecules to move inside the glass.[68] MD simulations also suggest that water will preferentially interact with the $\mathrm{Na}^{+}-\mathrm{NBO}$ site over the $\mathrm{BO}$ site at the surface to allow 
water molecules to penetrate into the glass.[69] Thus, the low $E_{a}$ value implies a reactionassisted penetration of water molecules into the SLS glass network and formation of Si-OH. Pure silica glass does not have leachable monovalent ions like $\mathrm{Na}^{+}$, which makes it thermodynamically difficult for molecular water to diffuse into the glass network and form $\mathrm{Si}$ OH groups.

The changes in the silicate network and increase in the amount of hydrous species in the surface region of SLS glass after hydrothermal treatment can explain the lower hardness of the surface layer (Figure 4). The hydrated silica-like layer with the lower hardness could suppress crack opening during the Vickers indentation test (Figure 5b). Based on the hypothesis involving the leachable sodium ions, the loss of mechanochemial wear resistance at high relative humidity can be explained by the depletion of sodium ions and the modification of the subsurface silicate network after hydrothermal treatments (Figure 6).

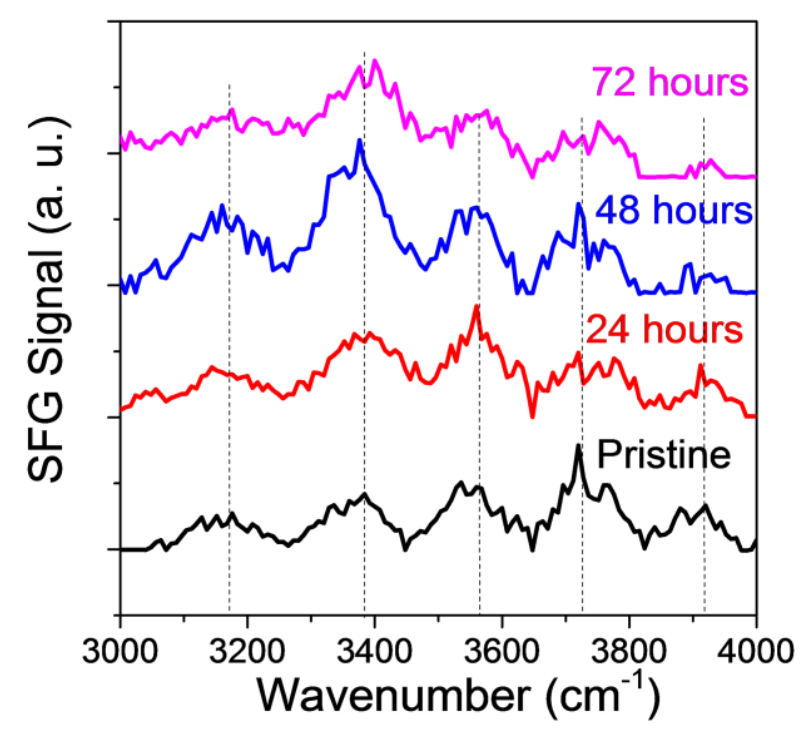


Figure 8. SFG spectra of SLS glass before and after hydrothermal treatment at $150{ }^{\circ} \mathrm{C}$ for 24 hours, 48 hours and 72 hours respectively.

SFG is very sensitive to chemical environments of the hydrous species $\left(\mathrm{Si}-\mathrm{OH}\right.$ and $\left.\mathrm{H}_{2} \mathrm{O}\right)$ arranged noncentrasymmetrically at the surface and in the subsurface region of SLS glass.[54,70] The $\mathrm{SO}_{2}$ dealkalization process of the manufactured float glass produces the subsurface hydrous species arranged or oriented noncentrosymmtrically which can be selectively detected with SFG as multiple sharp peaks in the $\mathrm{OH}$ stretch region.[70] Figure 8 shows the effect of hydrothermal treatment on these hydrous species in a $1 \mathrm{~mm}$ thick SLS float glass. Before hydrothermal treatment, this SLS float glass shows five OH peaks at $\sim 3180 \mathrm{~cm}^{-1}, \sim 3392 \mathrm{~cm}^{-1}, \sim 3552 \mathrm{~cm}^{-1}$, $\sim 3728 \mathrm{~cm}^{-1}$, and $\sim 3920 \mathrm{~cm}^{-1}$. These SFG peaks represent hydrous species in the subsurface of SLS glass rather than physisorbed water molecules on top of the glass.[58,70,71] SFG intensities depend on the noncentrosymmetrically-ordered species in a complex manner; so, the accurate quantification of the detected species is difficult. Instead, the most useful information can be deduced from the peak positions and relative intensities of the detected $\mathrm{OH}$ vibrations.[54,70]

The peak at $\sim 3728 \mathrm{~cm}^{-1}$ must be the free $\mathrm{OH}$ groups without hydrogen bonding interactions with surrounding oxygen species.[59] The peak above $3800 \mathrm{~cm}^{-1}$ is proposed to originate from the hydrous species (probably $\mathrm{OH}$ group) within the strained $\mathrm{Si}-\mathrm{O}-\mathrm{Si}$ network.[70,72-75] These strained sites in the silicate network would be more reactive than normal sites with bond distances and angles close to the equilibrium values; thus, they are expected to react more readily with water during the hydrothermal treatment, which would result in the selective disappearance of this peak after the hydrothermal treatment. 
The peaks at $<3650 \mathrm{~cm}^{-1}$ are the hydrous groups with varying degrees of hydrogen bonding interactions.[61,76,77] In Figure 8, the SFG peak at $\sim 3392 \mathrm{~cm}^{-1}$ is increasing compared to other peaks; similarly, the ATR-IR spectra in Figure $7 \mathrm{~b}$ show the largest increase at $\sim 3400 \mathrm{~cm}^{-}$ 1. The $\mathrm{OH}$ stretch peak position can be correlated with the $\mathrm{O}-\mathrm{H} \cdots \mathrm{O}$ distance using the empirical relationship found from minerals.[61]'[70] Using the empirical relationship found in the literature,[61]'[70] the component near $3400 \mathrm{~cm}^{-1}$ could be attributed to the hydrous species with hydrogen bonding interactions with the $\mathrm{O}-\mathrm{H} \cdots \mathrm{O}$ distance of $\sim 0.28 \mathrm{~nm}$. This value is very close to the equilibrium distance between two oxygen atoms connected via hydrogen bonds in liquid water; $[78,79]$ but this does not assure that the only species contributing to the $3400 \mathrm{~cm}^{-1}$ peak is molecular water. Not only the $\mathrm{OH}$ stretch peak position of molecular water, $[58,80]$ but also the $\mathrm{OH}$ stretch peak of the silanol group, vary over the same spectral range depending on the hydrogen bonding strength or distance.

With this spectral interpretation, we note that the distribution of the SFG OH peak intensities (Figure 8) is shifted to the lower wavenumber side, implying the growth of populations of hydrous species with shorter $\mathrm{O}-\mathrm{H} \cdots \mathrm{O}$ distances $\left(3400 \mathrm{~cm}^{-1}=0.28 \mathrm{~nm}\right.$ and 3250 $\left.\mathrm{cm}^{-1}=0.27 \mathrm{~nm}\right) \cdot[61]^{[}[70]$ This finding might provide an explanation for the loss of mechanochemical wear resistance. Density functional theory (DFT) calculations reported that at the transition state of the proton-catalyzed hydrolysis of the $\mathrm{Si}-\mathrm{O}-\mathrm{Si}$ linkage, the distance between the oxygen of a hydronium ion and the $\mathrm{BO}$ atom is about $0.25 \mathrm{~nm}$.[81]

One potential effect of the shear force exerted by the counter-surface during the wear test could be the distortion of the silicate network of SLS glass at the sliding interface, so that the distance between the hydrous species and the $\mathrm{BO}$ is reduced further toward $0.25 \mathrm{~nm}$. If so, the hydrolysis reaction could be facilitated during the interfacial shear. If the hydrous species with 
short $\mathrm{O}-\mathrm{H} \cdots \mathrm{O}$ distances are highly populated at the sliding interface, the transition state for hydrolysis could be reached with a small distortion of the silicate network. This hypothesis could be one possible explanation for the increased wear of the hydrothermal-treated surface at high humidity (Figure 6). Further details of this mechanochemical reaction mechanism could be revealed through computation studies such as molecular dynamics simulations with reactive force fields.

\section{Conclusions}

The surface of SLS float glass was probed and modified by hydrothermal treatment in steam which involved penetration and diffusion of water molecules, hydrolysis reaction of bridging oxygen, and ion-exchange between $\mathrm{Na}^{+}$and hydronium ions/protons. It was found that hydrothermal treatment at $>150^{\circ} \mathrm{C}$ can be used to reveal the subsurface damage of SLS glass since the area with subsurface damage or residual stress is preferentially hydrolyzed during the hydrothermal treatment. Hydrothermal treatment also creates a highly-hydrated silica-like layer with very little sodium. While the hardness of this modified surface layer is smaller than that of the bulk, the overall indentation fracture toughness of the glass surface increases. The hydrothermally-treated surfaces, unlike pristine SLS glass, become more susceptible to mechanochemical wear at high humidity. A hypothesis explaining the mechanochemical reactions leading to wear is proposed. 
Acknowledgements. This work was supported by the National Science Foundation (grant No. DMR-1207328). The authors acknowledge Asahi Glass Inc. for providing the samples for this study.

\section{References}

[1] J.R. Varner, H.J. Oel, Surface defects: Their origin, characterization and effects on strength, J. Non. Cryst. Solids. 19 (1975) 321-333. doi:10.1016/0022-3093(75)90097-6.

[2] J. Neauport, C. Ambard, P. Cormont, N. Darbois, J. Destribats, C. Luitot, et al., Subsurface damage measurement of ground fused silica parts by HF etching techniques., Opt. Express. 17 (2009) 20448-20456. doi:10.1364/OE.17.020448.

[3] K.O. Kese, Z.C. Li, B. Bergman, Influence of residual stress on elastic modulus and hardness of soda-lime glass measured by nanoindentation, J. Mater. Res. 19 (2004) 3109_ 3119. doi:10.1557/JMR.2004.0404.

[4] N.D. Surdyka, C.G. Pantano, S.H. Kim, Environmental effects on initiation and propagation of surface defects on silicate glasses: scratch and fracture toughness study, Appl. Phys. A. 116 (2014) 519-528. doi:10.1007/s00339-014-8552-7.

[5] A. Alazizi, A.J. Barthel, N.D. Surdyka, J. Luo, S.H. Kim, Vapors in the ambient-A complication in tribological studies or an engineering solution of tribological problems?, Friction. 3 (2015) 85-114. doi:10.1007/s40544-015-0083-5.

[6] A.J. Barthel, S.H. Kim, Lubrication by physisorbed molecules in equilibrium with vapor at ambient condition: Effects of molecular structure and substrate chemistry, Langmuir. 30 
(2014) 6469-6478. doi:10.1021/la501049z.

[7] K. Kese, D.J. Rowcliffe, Nanoindentation method for measuring residual stress in brittle materials, J. Am. Ceram. Soc. 86 (2003) 811-816. doi:10.1111/j.11512916.2003.tb03380.x.

[8] A. Kassir-Bodon, T. Deschamps, C. Martinet, B. Champagnon, J. Teisseire, G. Kermouche, Raman Mapping of the Indentation-Induced Densification of a Soda-LimeSilicate Glass, Int. J. Appl. Glas. Sci. 3 (2012) 29-35. doi:10.1111/j.20411294.2012.00078.x.

[9] Y. Kato, H. Yamazaki, S. Yoshida, J. Matsuoka, Effect of densification on crack initiation under Vickers indentation test, J. Non. Cryst. Solids. 356 (2010) 1768-1773. doi:10.1016/j.jnoncrysol.2010.07.015.

[10] H. He, S.H. Kim, L. Qian, Effects of contact pressure, counter-surface and humidity on wear of soda-lime-silica glass at nanoscale, Tribol. Int. 94 (2016) 675-681. doi:10.1016/j.triboint.2015.10.027.

[11] M. Ciccotti, Stress-corrosion mechanisms in silicate glasses, J. Phys. D. Appl. Phys. 42 (2009) 1-18. doi:10.1088/0022-3727/42/21/214006.

[12] F. Célarié, M. Ciccotti, C. Marlière, Stress-enhanced ion diffusion at the vicinity of a crack tip as evidenced by atomic force microscopy in silicate glasses, J. Non. Cryst. Solids. 353 (2007) 51-68. doi:10.1016/j.jnoncrysol.2006.09.034.

[13] S.M. WIEDERHORN, L.H. BOLZ, Stress Corrosion and Static Fatigue of Glass, J. Am. Ceram. Soc. 53 (1970) 543-548. doi:10.1111/j.1151-2916.1970.tb15962.x. 
[14] S.W. Freiman, G.S. White, E.R. Fuller, Environmentally Enhanced Crack Growth in Soda-Lime Glass, J. Am. Ceram. Soc. 68 (1985) 108-112. doi:10.1111/j.11512916.1985.tb09646.x.

[15] C. Ronchetti, M. Lindqvist, C. Louter, G. Salerno, Stress-corrosion failure mechanisms in soda-lime silica glass, Eng. Fail. Anal. 35 (2013) 427-438. doi:10.1016/j.engfailanal.2013.03.028.

[16] L. Wong, T. Suratwala, M.D. Feit, P.E. Miller, R. Steele, The effect of HF/NH4F etching on the morphology of surface fractures on fused silica, J. Non. Cryst. Solids. 355 (2009) 797-810. doi:10.1016/j.jnoncrysol.2009.01.037.

[17] F.M. Ezz-Eldin, T.D. Abd-Elaziz, N.A. Elalaily, Effect of dilute HF solutions on chemical, optical, and mechanical properties of soda-lime-silica glass, J. Mater. Sci. 45 (2010) 5937-5949. doi:10.1007/s10853-010-4679-x.

[18] H. He, J. Luo, L. Qian, C.G. Pantano, S.H. Kim, Thermal Poling of Soda-Lime Silica Glass with Nonblocking Electrodes-Part 2: Effects on Mechanical and Mechanochemical Properties, J. Am. Ceram. Soc. 8 (2016). doi:10.1111/jace.14080.

[19] L.C. Bradley, Z.R. Dilworth, A.L. Barnette, E. Hsiao, A.J. Barthel, C.G. Pantano, et al., Hydronium ions in soda-lime silicate glass surfaces, J. Am. Ceram. Soc. 96 (2013) 458463. doi:10.1111/jace.12136.

[20] H. He, L. Qian, C.G. Pantano, S.H. Kim, Mechanochemical Wear of Soda Lime Silica Glass in Humid Environments, J. Am. Ceram. Soc. 97 (2014) 2061-2068. doi:10.1111/jace.13014. 
[21] R.J. Charles, Static Fatigue of Glass. I, J. Appl. Phys. 29 (1958) 1554. doi:10.1063/1.1722992.

[22] S.M. Wiederhorn, F. Yi, D. LaVan, L.J. Richter, T. Fett, M.J. Hoffmann, Volume Expansion Caused by Water Penetration into Silica Glass, J. Am. Ceram. Soc. 98 (2015) 78-87. doi:10.1111/jace.13264.

[23] A. Oehler, M. Tomozawa, Water diffusion into silica glass at a low temperature under high water vapor pressure, J. Non. Cryst. Solids. 347 (2004) 211-219. doi:10.1016/j.jnoncrysol.2004.07.013.

[24] P.J. Lezzi, Q.R. Xiao, M. Tomozawa, T. a. Blanchet, C.R. Kurkjian, Strength increase of silica glass fibers by surface stress relaxation: A new mechanical strengthening method, J. Non. Cryst. Solids. 379 (2013) 95-106. doi:10.1016/j.jnoncrysol.2013.07.033.

[25] X. Liu, J. He, One-step hydrothermal creation of hierarchical microstructures toward superhydrophilic and superhydrophobic surfaces, Langmuir. 25 (2009) 11822-11826. doi:10.1021/la901426r.

[26] M.H. Krohn, J.R. Hellmann, D.L. Shelleman, C.G. Pantano, G.E. Sakoske, F. Corporation, Biaxial Flexure Strength and Dynamic Fatigue of Soda - Lime - Silica Float Glass, J. Am. Ceram. Soc. 85 (2002) 1777-1782. doi:10.1111/j.1151-2916.2002.tb00352.x.

[27] A.J. Barthel, J. Luo, K.S. Hwang, J.-Y. Lee, S.H. Kim, Boundary lubrication effect of organic residue left on surface after evaporation of organic cleaning solvent, Wear. 350351 (2016) 21-26. doi:10.1016/j.wear.2015.12.010.

[28] C.M. Lee, N.M.A. Mohamed, H.D. Watts, J.D. Kubicki, S.H. Kim, Sum-frequency- 
generation vibration spectroscopy and density functional theory calculations with dispersion corrections (DFT-D2) for cellulose I $\alpha$ and I $\beta$, J. Phys. Chem. B. 117 (2013) 6681-6692. doi:10.1021/jp402998s.

[29] G.C. Smith, Evaluation of a simple correction for the hydrocarbon contamination layer in quantitative surface analysis by XPS, J. Electron Spectros. Relat. Phenomena. 148 (2005) 21-28. doi:10.1016/j.elspec.2005.02.004.

[30] W.-T. Han, M. Tomozawa, Indentation Creep of Na2O*3SiO2 Glasses with Various Water Contents, J. Am. Ceram. Soc. 73 (1990) 3626-3632.

[31] A.J. Barthel, S.H. Kim, Lubrication by physisorbed molecules in equilibrium with vapor at ambient condition: Effects of molecular structure and substrate chemistry, Langmuir. 30 (2014) 6469-6478. doi:10.1021/la501049z.

[32] T.A. MICHALSKE, S.W. FREIMAN, A Molecular Mechanism for Stress Corrosion in Vitreous Silica, J. Am. Ceram. Soc. 66 (1983) 284-288. doi:10.1111/j.11512916.1983.tb15715.x.

[33] S.W. Freiman, S.M. Wiederhorn, J.J. Mecholsky, Jr., Environmentally Enhanced Fracture of Glass: A Historical Perspective, J. Am. Ceram. Soc. 92 (2009) 1371-1382. doi:10.1111/j.1551-2916.2009.03097.x.

[34] E.A. Leed, C.G. Pantano, Computer modeling of water adsorption on silica and silicate glass fracture surfaces, J. Non. Cryst. Solids. 325 (2003) 48-60. doi:10.1016/S00223093(03)00361-2.

[35] K. Zeng, D. Rowcliffe, Experimental Measurement of Residual Stress Field around Sharp 
Indentation in Glass, J. Am. Ceram. Soc. 77 (1994) 524-530. doi:10.1111/j.11512916.1994.tb07025.x.

[36] B.R. LAWN, K. JAKUS, A.C. GONZALEZ, Sharp vs Blunt Crack Hypotheses in the Strength of Glass: A Critical Study Using Indentation Flaws, J. Am. Ceram. Soc. 68 (1985) 25-34. doi:10.1111/j.1151-2916.1985.tb15246.x.

[37] G.M. Pharr, W.C. Oliver, Measurement of Thin Film Mechanical Properties Using Nanoindentation, MRS Bull. 17 (1992) 28-33. doi:10.1557/S0883769400041634.

[38] T.Y. Tsui, G.M. Pharr, Substrate effects on nanoindentation mechanical property measurement of soft films on hard substrates, J. Mater. Res. 14 (1999) 292-301. doi:10.1557/JMR.1999.0042.

[39] Y. V. Milman, A.A. Golubenko, S.N. Dub, Indentation size effect in nanohardness, Acta Mater. 59 (2011) 7480-7487. doi:10.1016/j.actamat.2011.08.027.

[40] M. Patschger, C. Rüssel, Sodium/potassium ion exchange of a soda-lime-silica float glass: Mechanical strength, hardness, stress profile and thickness of the ion exchanged layer, Glas. Technol. Eur. J. Glas. Sci. Technol. Part A. 56 (2015) 163-170. doi:10.13036/17533546.56.5.163.

[41] M.M. Smedskjaer, M. Bauchy, Sub-critical crack growth in silicate glasses: Role of network topology, Appl. Phys. Lett. 107 (2015). doi:10.1063/1.4932377.

[42] O. Laurent, B. Mantisi, M. Micoulaut, Structure and topology of soda-lime silicate glasses: Implications for window glass, J. Phys. Chem. B. 118 (2014). doi:10.1021/jp506155p.

[43] L. Chen, Y.J. Yang, H.T. He, S.H. Kim, L.M. Qian, Effect of coadsorption of water and 
alcohol vapor on the nanowear of silicon, Wear. 332-333 (2015) 879-884.

doi:10.1016/j.wear.2015.02.052.

[44] H. He, L. Qian, C.G. Pantano, S.H. Kim, Effects of humidity and counter-surface on tribochemical wear of soda-lime-silica glass, Wear. 342-343 (2015) 100-106. doi:10.1016/j.wear.2015.08.016.

[45] J. Yeon, A.C.T. van Duin, S.H. Kim, Effects of Water on Tribochemical Wear of Silicon Oxide Interface: Molecular Dynamics (MD) Study with Reactive Force Field (ReaxFF), Langmuir. (2016) acs.langmuir.5b04062. doi:10.1021/acs.langmuir.5b04062.

[46] R. Iler, The Chemistry of Silica. Solubility, Polymerization, Colloid and Surface Properties, and Biochemistry, John Wiley \& Sons, Inc., 1979. http://books.google.com.hk/books?id=eKwOKQEACAAJ.

[47] B.C. Bunker, Molecular mechanisms for corrosion of silica and silicate glasses, J. Non. Cryst. Solids. 179 (1994) 300-308. doi:10.1016/0022-3093(94)90708-0.

[48] T. Chuang, E.R. Fuller, Extended Charles-Hillig theory for stress corrosion cracking of glass, J. Am. Ceram. Soc. 75 (1992) 540-545. doi:10.1111/j.1151-2916.1992.tb07839.x.

[49] T. Akai, K. Kuraoka, D. Chen, Y. Yamamoto, T. Shirakami, K. Urabe, et al., Leaching Behavior of Sodium from Fine Particles of Soda-Lime-Silicate Glass in Acid Solution, J. Am. Ceram. Soc. 88 (2005) 2962-2965. doi:10.1111/j.1551-2916.2005.00524.x.

[50] P.B. McGinnis, J.E. Shelby, Diffusion of water in float glass melts, J. Non. Cryst. Solids. 177 (1994) 381-388. doi:10.1016/0022-3093(94)90552-5.

[51] J.E. Shelby, A limited review of water diffusivity and solubility in glasses and melts, J. 
Am. Ceram. Soc. 91 (2008) 703-708. doi:10.1111/j.1551-2916.2007.01946.x.

[52] A. V. Bandura, The Ionization Constant of Water over Wide Ranges of Temperature and Density, J. Phys. Chem. Ref. Data. 35 (2006) 15. doi:10.1063/1.1928231.

[53] A.K. Covington, M.I.A. Ferra, R.A. Robinson, Ionic product and enthalpy of ionization of water from electromotive force measurements, J. Chem. Soc. Faraday Trans. 1 Phys. Chem. Condens. Phases. 73 (1977) 1721. doi:10.1039/f19777301721.

[54] J. Luo, H. He, N.J. Podraza, L. Qian, C.G. Pantano, S.H. Kim, Thermal Poling of SodaLime Silica Glass with Nonblocking Electrodes-Part 1: Effects of Sodium Ion Migration and Water Ingress on Glass Surface Structure, J. Am. Ceram. Soc. 99 (2016) 1221-1230. doi:10.1111/jace.14081.

[55] N.J. Smith, C.G. Pantano, Leached Layer Formation on Float Glass Surfaces in the Presence of Acid Interleave Coatings, J. Am. Ceram. Soc. 91 (2008) 736-744. doi:10.1111/j.1551-2916.2007.02079.x.

[56] S. Amma, J. Luo, C.G. Pantano, S.H. Kim, Specular reflectance (SR) and attenuated total reflectance (ATR) infrared (IR) spectroscopy of transparent flat glass surfaces: A case study for soda lime float glass, J. Non. Cryst. Solids. 428 (2015) 189-196. doi:10.1016/j.jnoncrysol.2015.08.015.

[57] S. Amma, S.H. Kim, C.G. Pantano, Analysis of Water and Hydroxyl Species in Soda Lime Glass Surfaces Using Attenuated Total Reflection (ATR)-IR Spectroscopy, J. Am. Ceram. Soc. 99 (2016) 128-134. doi:10.1111/jace.13856.

[58] D.B. Asay, S.H. Kim, Evolution of the adsorbed water layer structure on silicon oxide at 
room temperature., J. Phys. Chem. B. 109 (2005) 16760-16763. doi:10.1021/jp053042o.

[59] Q. Du, E. Freysz, Y.R. Shen, Surface vibrational spectroscopic studies of hydrogen bonding and hydrophobicity., Science. 264 (1994) 826-828. doi:10.1126/science.264.5160.826.

[60] A.M. Efimov, V.G. Pogareva, A. V. Shashkin, Water-related bands in the IR absorption spectra of silicate glasses, J. Non. Cryst. Solids. 332 (2003) 93-114. doi:10.1016/j.jnoncrysol.2003.09.020.

[61] E. Libowitzky, Correlation of O-H Stretching Frequencies and O-H $\cdots$ O Hydrogen Bond Lengths in Minerals, Monatshefte Fuer Chemie/Chemical Mon. 130 (1999) 1047. doi:10.1007/s007060050263.

[62] H. Wang, M.J. DelloStritto, N. Kumar, A.I. Kolesnikov, P.R.C. Kent, J.D. Kubicki, et al., Vibrational Density of States of Strongly H-Bonded Interfacial Water: Insights from Inelastic Neutron Scattering and Theory, J. Phys. Chem. C. 118 (2014) 10805-10813. doi:10.1021/jp500954v.

[63] K.M.M. Davis, M. Tomozawa, An infrared spectroscopic study of water-related species in silica glasses, J. Non. Cryst. Solids. 201 (1996) 177-198. doi:10.1016/00223093(95)00631-1.

[64] G. Navarra, I. Iliopoulos, V. Militello, S.G. Rotolo, M. Leone, OH-related infrared absorption bands in oxide glasses, J. Non. Cryst. Solids. 351 (2005) 1796-1800. doi:10.1016/j.jnoncrysol.2005.04.018.

[65] E.T.J. Nibbering, T. Elsaesser, Ultrafast Vibrational Dynamics of Hydrogen Bonds in the 
Condensed Phase, Chem. Rev. 104 (2004) 1887-1914. doi:10.1021/cr020694p.

[66] A. Zouine, O. Dersch, G. Walter, F. Rauch, Diffusivity and solubility of water in silica glass in the temperature range $23-200^{\circ} \mathrm{C}$, Glas. Sci. Technol. 48 (2007) 85-91.

[67] K.M. Davis, M. Tomozawa, Water diffusion into silica glass: Structural changes in silica glass and their effect on water solubility and diffusivity, J. Non. Cryst. Solids. 185 (1995) 203-220. doi:10.1016/0022-3093(95)00015-1.

[68] A. Tilocca, N. de Leeuw, A. Cormack, Shell-model molecular dynamics calculations of modified silicate glasses, Phys. Rev. B. 73 (2006) 104209. doi:10.1103/PhysRevB.73.104209.

[69] A. Tilocca, A.N. Cormack, Modeling the Water-Bioglass Interface by Ab Initio Molecular Dynamics Simulations, ACS Appl. Mater. Interfaces. 1 (2009) 1324-1333. doi:10.1021/am900198t.

[70] J. Luo, J. Banerjee, C.G. Pantano, S.H. Kim, Vibrational Sum Frequency Generation Spectroscopy Study of Hydrous Species in Soda Lime Silica Float Glass, Langmuir. 2 (2016) acs.langmuir.6b00706. doi:10.1021/acs.langmuir.6b00706.

[71] A. Luzar, D. Chandler, Hydrogen-bond kinetics in liquid water, Nature. 379 (1996) 55-57. doi: $10.1038 / 379055 \mathrm{a} 0$.

[72] X. Li, L. Liu, H.B. Schlegel, On the physical origin of blue-shifted hydrogen bonds, J. Am. Chem. Soc. 124 (2002) 9639-9647. doi:10.1021/ja020213j.

[73] J. Joseph, E.D. Jemmis, Red-, blue-, or no-shift in hydrogen bonds: A unified explanation, J. Am. Chem. Soc. 129 (2007) 4620-4632. doi:10.1021/ja067545z. 
[74] M. J., FTIR techniques in clay minerals studies: A review, Vib. Spectrosc. 31 (2003) 1. doi:10.1016/S0924-2031(02)00065-6.

[75] G. Della Ventura, A. Marcelli, F. Bellatreccia, SR-FTIR Microscopy and FTIR Imaging in the Earth Sciences, Rev. Mineral. Geochemistry. 78 (2014) 447-479. doi:10.2138/rmg.2014.78.11.

[76] Y. Maréchal, Infrared and Related Spectroscopies of H-Bonded Systems: Experimental Point of View, in: Hydrog. Bond Water Mol., Elsevier, 2007: pp. 77-113. doi:10.1016/B978-044451957-3.50005-6.

[77] Q. Du, E. Freysz, Y.R. Shen, Vibrational spectra of water molecules at quartz/water interfaces, Phys. Rev. Lett. 72 (1994) 238-241. doi:10.1103/PhysRevLett.72.238.

[78] K. Modig, B.G. Pfrommer, B. Halle, Temperature-dependent hydrogen bond geometry in liquid water, Phys. Rev. Lett. 90 (2003) 75502. doi:10.1103/PhysRevLett.90.075502.

[79] R.C. Dougherty, Temperature and pressure dependence of hydrogen bond strength: A perturbation molecular orbital approach, J. Chem. Phys. 109 (1998) 7372-7378. doi:10.1063/1.477343.

[80] D.B. Asay, S.H. Kim, Effects of adsorbed water layer structure on adhesion force of silicon oxide nanoasperity contact in humid ambient, J. Chem. Phys. 124 (2006) 174712. doi:10.1063/1.2192510.

[81] L.J. Criscenti, J.D. Kubicki, S.L. Brantley, Silicate Glass and Mineral Dissolution: Calculated Reaction Paths and Activation Energies for Hydrolysis of a Q3 Si by H3O + Using Ab Initio Methods, J. Phys. Chem. A. 110 (2006) 198-206. doi:10.1021/jp044360a. 